\title{
The Shift in Marketing Based on Emerging Customer Experience
}

Author: Sanjay Kumar, Research Scholar, Singhania University, Department of Management

Co-author Dr. Prasun Kumar, Assistant Professor, Department of Management.

\section{Abstract}

The world of selling has been evolving drastically in the past twenty years. The evolution of Customer Experience has modified the entire paradigm of shopping. The impetus has shifted towards a customercentric approach and keeping the customer above everything. The appearance of social media, self-service technologies, and numerous alternative digital advancements has modified the shopper's behavior. Digital and analytics have emerged as key enablers for promoting products and services. Business organizations try to harness the advantages of those advancements. The role of the customer has evolved quite considerably as an enabler within the overall success of a product/brand. The managers currently need new tools to live and perceive the performance of the organization in totality. The current review paper examines the rumored work on the evolution of customer experience management and provides a theoretical framework for a comparative understanding of changes/shifts in customer experience management and promoting the products and services.

Keywords: Customer experience, customer insights \& analytics, Omnichannel, self-service technologies, customer journey.

Introduction

Consumer's behavior is primarily concerned with, the study of how individuals make their decisions to spend their available resources (Time, effort, and money) or it is concerned with the study of consumption-related aspects i.e. What they buy? When do they buy? How do they buy? How much they buy etc.

The buying motives of the consumers can be divided into Product Motives and Patronage Motives. Product motives may be defined as those impulses, desires, and considerations which make the buyer purchase a product. These may still be classified on the basis of the nature of satisfaction: Emotional Product Motives and Rational Product Motives.

Patronage motives may be defined as considerations or impulses which persuade the buyer to patronage specific shops. Just like product motives, patronage can also be grouped as emotional and rational. 
In general, the consumers are categorized as involved and not involved in products and shopping, whereas when we talk about fashion apparel shopping the consumers are involved and highly involved in products and shopping. The consumers who are highly involved with a product or service would be interested in knowing a lot more about it before purchasing.

The present study is very important as it's going to help the brands/retailers to understand the Impact of Sensory/Experiential Marketing (Schmitt Model) on Fashion Consumer Buying Decision Making because as we know that the fashion apparel customers of the present world are aware, intelligent and very particular about their consumption. They expect to consume and experience the best products and services at the most suitable prices, which is making the task of the designers, manufacturers, and retailers of fashion products very difficult.

The fashion apparel consumers today are bombarded with plenty of products and services for their needs by multiple retailers/ service providers if we look at the products offered as well as the prices there is hardly any difference, In fact, the products are coming from one brand, which is sold by various retailers at the same prices, which makes the decision making for purchase difficult for the customer whether to buy from a particular retailer/ brand store or its competitor. The same promotion and advertising tools are used by the retailers/manufacturers to attract and serve the consumers.

The retailers/manufacturers are finding it very difficult to retain and keep their customers loyal to their stores/brands. The fashion consumer at present does not only expect to buy a product but also wants to get treated well and want an experience that is not commonly offered by the retailers.

Further, the brands/retailers are expecting that the customers who come to their stores (or consume their products in case of brands) are not only just consumers or buyers but they expect them to become the brand advocates who talk good about the products and experience they receive and suggest their friends and acquaintance to use the products offered by the particular retailer/brand, which is pushing them to look for new techniques and ways to make their customers loyal to their brand.

The concept of experiential marketing is a recent development in this area, which seems to be relevant in the present environment and can help retailers to work in the direction of customer acquisition to customer advocacy. The concept is well established in the area of hospitability.

If we look at the Indian market the concept of experiential marketing was practiced in bits and pieces by the retailers/brands as they were not following a particular framework in this area. At present we see very few retailers in India who are following experiential marketing concept or model e.g. Fab India, Muji, Miniso, Bhaane, Napa Dori etc.

\section{Experiential Marketing}

Experiential Marketing essentially refers to the process through which a retailer/brand identifies the needs of consumers and satisfies those needs well as the underlying actions that build relationships between the clients 
and the retailer/brand. Crucially, the experiential marketing revolves around the process of engaging with the customers with the retailers/ brand through a two-way mode of interaction.

As stated by Schmitt about Experiential marketing = “.... any form of customer-focused marketing activity that creates a connection to customers is experiential marketing" (Schmitt, 2011)

In the words of Lenderman -Today's consumer wants value-enhancing, memorable marketing experiences that "dazzle their senses, touch their hearts, and stimulate their minds" (Lenderman, 2007, p. 18-19)

Holbrook and Hirschman (1982) believed that experiential sight of consumption as an alternative to the customer's information-processing perspective. According to these authors Fantasies, Feelings, and Fun (3Fs) are the goals and criteria for brands successful consumption in the experiential view. In other words, in experiential consumption, the rational, calculative and goal-directed customer of the informationprocessing model turns to a customer's pleasure-directed individual that continuously looks for enjoyment, amusement, and "sensory-emotive" stimulation.

According to Kotler (2003), there are two types of marketing: one traditional marketing and the second modern marketing. Modern marketing has overtaken traditional marketing due to the concentration on the newly emerged concepts of experiential marketing and customer experiences.

Ms. Molly Galetto in her article (2017) what is experiential marketing has tried to give a comprehensive definition of Experiential Marketing in her words "Experiential Marketing is an advertising strategy that focuses on helping consumers experience a brand, experiential marketing veers off course from traditional strategies that broadcast brand and product benefits to a wide audience. Also referred to as engagement marketing, experiential marketing may be comprised of a variety of marketing strategies geared toward immersing customers within the product by engaging them in as many ways as possible."

Experiential Marketing is marketing strategy that engages the consumer and creates real-life experience that will be remembered by them. Experiential marketing focuses on getting the consumers to experience and feel the brand.

The decision-makers in retail are well aware of the value that experiential marketing can bring to their respective brands. The relationship between a customer and seller is a complex one and has an impact on the customer on a very psychological level. People don't want to be seen as a "demographic target" or "users" but as an individual. This helps in strengthening the sales and build loyalty and enthusiasm among customers.

Experiential marketing promotion of services and actions that showcase a brand's/retailers' media campaigns, lifestyle displays, traveling display as well as live item experiences in order to market and promote a product. Essentially, based on the theme of retail marketing through the aspects espoused by experiential marketing, business ventures should come up with memorable events meant to resonate with the feelings and experiences of their customers. Practically, the memories entrenched in the shoppers as a result of experiential marketing turns into the crucial pillar and element that acts as the product itself - to an extent; the experience becomes the perfect product. 
Therefore, "Customer experience is not an initiate; it's a change in the mindset." It is a fact that human beings enjoy being around other human beings. Talking to fellows alike increases well-being, generates new feelings and influences one's thoughts and beliefs. This is one big reason why brick and mortar stores are still holding a strong foothold despite the online activity surge. Brands are beginning to realize that to attract the offline customer, the space that the retail store occupies must be inviting enough to drag their customers away from their phones and tablets and back to reality.

Customers today don't just want products; on a personal level, what matters to them is a need to create meaningful memories. Narratives help people in comprehending themselves and thus make sense of the complex world around them. Owing to this concept, the term 'experiential marketing' has become a necessity for retailers/brands. Experiential marketing drives word-of-mouth marketing because if you provide consumer a good experience, they tend to talk about it to their friends or post it on social media. Hosting offline events helps companies to get immediate customer feedback and get to observe how the consumer interacts with the services and products provided by you.

Conceptual framework of Experiential Marketing by Schmitt

Competitive advantage is a combination of features and experiences that customers expect and only a particular retailer/brand can provide, which makes their business more attractive than the competition. In the Traditional marketing approach, the retailers/brands focus on building the competitive advantage using 4Ps i.e. Price, product, place, promotion by delivering goods to customers better, cheaper, or faster and look at the consumer as logical, information processor who always make a decision as per his/her requirement.

On the other hand, Schmitt is an influential author in the field of customer experiences management that argues that traditional marketing techniques will need to give place to the newer concept of experience marketing. Whereas traditional marketing is focused on selling the functional features and benefits of a product, experience marketing emphasizes the creation of holistic and stimulating experiences within each marketing medium.

"The Bernd Schmitt Experience" Schmitt describes that what matters for a retailer /brand is making something memorable for the customers = making a positive experience easy to recall or remember at will. The only thing people enjoy more than ease and comfort is the existence of a good story, that good story can 
be told as five types of experiences in experiential marketing, which help in creating the memorable experience i.e., sense, feel, think, act and relate.

SENSE- refers to Sensory experiences in which the consumer's senses of sight, hearing, taste, touch, and smell are stimulated separately or in combination. The objective of sensory strategies, according to Schmitt, is to "provide aesthetic pleasure, excitement, beauty, and satisfaction through sensory stimulation." Sensory experiences are used to provide aesthetic feels.

FEEL- refers to Affective experiences, which elicit emotions and feelings in consumers, this is used by brands/retailers for proper use of feel in advertising targets the emotional state of someone during "consumption which elicits emotions and feelings in consumers"

THINK- refers to Creative Cognitive experiences, which involve consumers in creative problem-solving tasks, think strategies appeal to customers' intellect, they are cognitive experiences, which provide opportunities to address major issues, both personal and societal. They have components of surprise, trickery, and provocation.

ACT- refers to physical experience which offers consumers alternative behavior and lifestyle models with a mix of logic and cultural expression.

RELATE- refers to social identity experiences based on social dimensions, innate research for belonging, and meaning. The retailers/ brands use Relate strategies to draw upon our innate search for belonging and meaning

Bernd Schmitt views on customer experience, branding, and innovation set forth some rules for successful experiential marketing, which are: -

1. Dynamism - Adding Dynamism and "Dionysian's" to the company and brand. Most organizations and brand owners are too timid, too slow, and too bureaucratic. The term "Dionysian" is associated with the ecstatic, the passionate, the creative. The plush and one of its kind set of the Plum communicates ecstasy and creativity.

2. Extension - This focuses on how experiences change when the brand extends by leveraging into different categories. Plum brings together the two utmost pleasures of life, fine dine and shopping. 
3. "EJ" Experience - According to Schmitt, Traditional Models miss the 'Exultate Jubilate' Experience. Plum delights the customer in exultant jubilation. Since from decor to furniture, everything one sees is up for grabs, one can actually imagine deciding the decor for their living room while sipping on exotic cocktails!

4. Planning - Experiences don't just happen; they need to be planned. By incorporating the elements of surprise and provocation, Plum provides an enchanting experience to the guests.

\section{Critical Evaluation of Schmitt Model of Experiential Marketing}

Some of the critiques of the Bernd Schmitt model are-

Experiential marketing when extended to a global level may raise many issues. There might be cultural preferences and differences for types of strategic experiential modules. In one nation/culture people may prefer FEEL, while in a second culture people may prefer to RELATE, and THINK in the third one.

Experiences are really subjective and vary from person to person. There are cultural differences too when it comes to specific experiences. There should be a well-determined target group to enhance customer experiences.

The fact that whether different Experience providers appeal to different customers from different countries/ cultures differently.

In the strategic experiential module approach, there can be an issue with the intensity of an experience. There is a constant conflict of an experience being too intense or too diffusing. The focus point is- what is the perfect level of intensity for an experience to be enjoyable and have a positive impact on the customer, the level that avoids overdoing and not standing out. This balance is really difficult to maintain. For example, you may want to tap on the FEEL experience in a commercial. The question is- what is the optimum level of intensity to get viewers to dab their eyes and feel good about your brand and doesn't overdo it and look tacky.

There is a constant concern about enhancing or simplifying an experience. This includes whether an organization should enhance an experience by adding additional experience providers such as communication, visuals, etc. Or should they simplify an experience by sticking to certain limited experience providers? For instance, should a retail store provide an experiential FEEL environment, or should it adopt a more functional selling space?

The question of whether an organization should expand its experiential appeal from individual experiences to more Holistic experiences or whether the organization should focus on a unique single experience.

Another issue can be linkage. This involves interrelation among the strategic experiential modules (SEMs). The various SEMs need to be connected to one another and if there are too many experiences, they might become too broad. It may pose a risk of becoming too confusing to experience. So, it is better to separate 
experiences. For example, should Hallmark greeting cards create linkage and connection between its conventional FEEL approach and new THINK approach, by adding multimedia effect in their printed cards?

Conceptual framework of Experiential Marketing by Pine and Gilmore - In today's scenario, we all know that the consumer is king. The very core of the marketing strategies and plans adopted by various companies and brands is consumer satisfaction. The consumer nowadays is not simply satisfied with a product or service, they want more. More and more attention is being placed on experiences, and it can actually be regarded as a megatrend, and businesses are increasingly hopping on to this trend. Products and services that lack the entertainment component will soon fade away.

Experience can be simply defined as the process or fact of personally observing, encountering, or undergoing something. With an increased focus on the idea of self-perception, these experiences become a part of the stories that people tell about their lives. Immersive, memorable, and live, providing an experience to the customer to help deliver the brand campaigns can deliver their message without distractions. Marketers have realized the importance of engaging it's the audience to portray what the brand stands for. The idea of selling experiences is increasingly spreading beyond amusement parks and theatres.

Also known as engagement marketing, live marketing, or event marketing, experiential marketing is a strategy used by marketers to involve the consumer as a part of their campaigns. They use participatory, hands-on and tangible branding material to interact with their target audience in a real-world situation. At its core, it focuses on helping consumers experience a brand. The campaigns are mostly based on the traditional strategies that the company uses to communicate the product and benefits to a wide audience. The main objective of using such strategies is to form an emotional connection with the customers and foster brand loyalty and improve customer lifetime value (CLV).

B. Joseph Pine II and James H. Gilmore stressed the importance of creating memorable experiences for consumers and how these experiences or memories become a product in themselves. They were the first to use the term 'Experience Economy' in a 1998 article for the Harvard Business Review. This increasing importance of experiences could be because of the Increased competition as well as increasing consumer expectations. This shift from a 'Service Economy' to an 'Experience Economy' has been explained by Pine and Gilmore through a 'Progression of Economic value'. "This progression talks about how the focus has continuously shifted from extracting commodities that are transformed into goods, which are wrapped in services, and these services are ultimately staged as memorable experiences". This brings us from a traditional agrarian economy to an economy where experiences are given priority and are the major differentiating factor for brands and companies. Goods and services are no longer enough to satisfy and retain consumers. This could be better understood with the example of the progression of the economic value of coffee and the emergence of cafes specifically dedicated to serving coffees like Cafe Coffee Day, Starbucks, etc. Coffee is grown in Southern India. Initially, Coffee beans were extracted which forms the basic 
commodity and is the cheapest. When manufacturers process these coffee beans and sell them to grocery and convenience stores (Nescafe, brew, etc.), they become goods and add value to those coffee beans. When this coffee is served in restaurants and diners, it becomes a part of the services extended by them, increasing the price even further. The last stage of this progression is the emergence of cafes such as Cafe Coffee Day, which not only sells coffee, but an experience, as is made evident by their tagline, 'A lot can happen over coffee. This also allows Cafe Coffee Day to charge high prices for their coffees. Here the service provided, that is serving coffee, becomes the stage, and the goods, i.e., coffee that is sold become the props.

The core element of Pine and Gilmore's model is customer involvement, implying that the customer plays an integral role in creating the experience by interacting with the brand or company. "According to them, there are 4 main dimensions of experiences, depending upon 2 variables- Consumer's level of participation (Active or passive participation) and their interaction with the environment (Absorption or Immersion)". Passive participation is when the consumer has no involvement or control over what is happening. On the other end of the spectrum is active participation, wherein the customer is actively involved in and can influence the events or experiences that are taking place. On the other axis, on one end we have absorption, which refers to bringing the experience into the mind of the consumer in order to capture their attention. On the other end is Immersion, which means physically or virtually becoming a part of the event or experience itself.

The first dimension is Entertainment, where the customers participate more passively than actively and their connection with the environment or event is likely one of absorption than immersion. The second dimension is Esthetic, which also involves passive participation, but with a greater depth and immersion with respect to what is being seen or experienced. While the consumers are immersed in the event, they have little or no control over what is going on. The third dimension is Educational, which represents an experience that is being absorbed as it is happening but also requires active participation. The consumers are still more outside the event than being immersed in the action. The last dimension is Escapism, which refers to the experiences where the participant both becomes completely immersed in what is happening and participates actively. Escapist experiences can teach the consumers just as well as educational experiences, or amuse them just as well as entertainment, but they involve a greater degree of consumer immersion. We will now have a look at all these dimensions in detail, with the help of examples in the Indian context.

\section{Entertainment Dimension}

Some businesses use entertainment to provide a memorable experience to their consumers. It helps the brand to create a Brand Image and helps in promotion through word of mouth. Consumers passively observe activities and performances of others, their connection with the environment or event is one of absorption than immersion. Businesses have started focusing on giving their customers a memorable experience through 
entertainment. Hotels, resorts, restaurants, retail stores, and brands aim to provide their customers with different entertainment experiences. Hotels are no longer just a place to lodge and sleep. Today's hotel guest is looking for an experience. Clustering several fun facilities together on site creates a stronger attraction. Many hotels organize fun entertainment experiences for their customers where they organize cultural music and dance events, events for kids, concerts whereby customers are passively enjoying the performances and activities. Hotels of different countries and regions highlight their cultures through organizing events that highlight their cultures. Restaurants can provide customers with a good experience by organizing various entertainment events. Experiential retail is the future, retail experiences are on the rise. Many retail stores use foreground and background music for ambiance cues. Malls invite Bollywood celebrities to promote brands or for movie premiers for a better customer experience.

\section{Esthetical Dimension}

Esthetic is one of the four realms of the Experience Economy. Experiences in which consumers participate in a passive manner but are completely immersed in what they view and experience is known as the esthetic realm. These aim to create an attractive environment with sensory content for the consumers. Herein, the individuals immersed in an event or environment essentially cannot influence its outcomes. This dimension is used to create a feeling of harmony amongst the consumers, ensuring they have a pleasant memory of the experience. The creation of such an experience requires an environment containing a variety of different elements including ambient factors like color, the layout, air, scent, illumination, and the positioning of respective items. For a retail setting, the elements of the esthetic realm are the exterior, general interior, layout and design, point of purchase, and decor. These factors are all interrelated and they work together to create an ambiance that influences the consumers' memories, behaviors and thus, are successful in creating an experience to remember for the consumer. Under this experience, the consumer appreciates the sensoryrich environment but doesn't take part in the alteration of any element of the setting.

\section{Educational Dimension}

The educational dimension is aimed at providing an intellectually enriching experience to the customer by upgrading the consumer's knowledge and skills by active involvement. This is a significant aspect of experience since the consumer, apart from getting the value from goods and services, gets to learn something which he will remember about the brand. This creates a distinction about the brand which differentiates it from the other brands. Therefore, the educational experience is considered significant for the learning aspect involved in the process of experience.

Active interaction between the brand and the customer through informative engaging participation by the consumer helps develop a stronger impact on the customer's mind of the brand as he/she absorbs this intellectual experience. This also strengthens the brand-customer bond as the brand helps in the individual development of the customer. 
Key Aspects of Educational experience include:

-Intellectual Upgradation of consumer

-Active Participation of consumer

-Learning is involved in the process

-Providing a distinctive value that transcends the utility of goods or services offered by the brand.

Escapism Dimension:

Escapism is the use of invention, entertainment, art, music, celebration, and leisure in order to transcend everyday life's negative realities. It is also viewed negatively as avoidance of issues that need attention. Escapism has immense importance for well-being and society, as long as it does not go too far. Daydreaming is considered a beneficial imagination practice. Music or watching a movie can inspire excitement or provide a fresh viewpoint on issues. Brands that inspire creativity and feelings that are optimistic appear to sell more.

Escapist experiences lie in the quadrant of active immersion. Escapist experiences are where users actively participate in defining the experience and immerse themselves (e.g., games in virtual reality or leisure activities in order to become part of the activity.

For example, in terms of the retail aspect of shopping malls, as an escape experience for shoppers, retailers selling outdoor equipment for recreational activities can add target ranges or climbing walls. Escapist shopping experiences are identified as fun (Babin et al., 1994). Fiore and Ogle (2000) observed that the experience of consumption involves the development of an "alternative life," in which the user fantasizes about engaging in fun scenarios that include a product. The emotional and social significance can be affected by escape experiences from retail stores (e.g., rock climbing wall in-store) and non-store (e.g., amusement parks, interactive roller coasters, and car exhibitions) components of the shopping mall experience. Consumers considered shopping to be an escape from their everyday routine in Delhi malls; by playing a different role as rock climbers, they became part of the shopping experience outside their homes (Jamal, 2006). Joy is generated by such escapist experiences. Fun and relaxation add to the emotional importance of the mall experience.

Critical Analysis of the Pine and Gilmore Model

We can see how economic value has evolved from commodities to goods, services, and now to staging positive, engaging memorable experiences which have culminated as the most prevalent strategy in today's world. The customer experience has overtaken price and product as the key brand differentiator between brands. In general, the whole concept of the Experience economy can be seen as a marketing strategy that responds to the consumer's demands, preferences, and expectations in different contexts. In the modern world, the traditional marketing approaches that just have the functional attributes of the product and the quality are inadequate. Customers aspire for experiences that are engaging and stimulating. 
Various scholars have conceptualized the term customer experience in different ways. Pine and Gilmore conceived the idea of Customer Experience as the creation of memorable events.

Apart from providing the goods and services, it's equally important to stage them as an experience in the form of feeling, learning, being, and doing as reflected in the Pine and Gilmore model.

Pine and Gilmore model revolve around a human-centric approach which is the core element of businesses today. Customers want to be the action heroes of the brand they are using or vouching which enables them to relate and connect with the brand on a personal level and get the optimal emotional satisfaction. This model gives impetus to human connections, consciousness, and value creation. Value refers to the benefits that the customers reap not only from the goods and services, but also from interactions with the brands, people, and places, which help to shape the experience which is memorable and life-transforming. Creating such enriching and positive experiences is where qualities of vision, innovation, and a passion for change come into play which results in differentiation from competitors, large and small.

Although there is a multitude of different definitions there for customer experience, the essence is not captured holistically. A common thread that is woven through all the definitions is 'managing touchpoints. However, there is a colossal number of touchpoints that need to be managed and they have their dependence on a diverse number of factors including target market, competitors, marketing strategies, price. The list is never-ending and the articulation of all the factors together poses a difficulty.

There has been a sea of change that has occurred in consumerism in the past decades. The greatest challenge that the twenty-first-century marketers will be presented with is the need to create reality because the modern consumer will have new and varying definitions of "real," definitions that are not bound to destinations, but devices.

The foregone consumer had a destination for everything, for shopping, for recreational activities. The modern-day consumer has his whole world intertwined with technology.

Experiential stimulation and flexibility define the lives of Generation $\mathrm{Y}$ and Generation $\mathrm{Z}$ as opposed to Baby Boomers and Generation X. As the world surrounding the consumer becomes more commoditized, they need an additional reason to stay loyal. As the brands today compete for attention by following the strategy of the experience economy, the essence of experience is being lost. Customers are being bombarded with similar kinds of experiences and services. There is minimal exclusivity and the services offered by the brands are becoming homogeneous. Delivering authenticity becomes a new means of differentiation and maintaining customer loyalty.

The man himself Joseph Pine says "There's a paradox at work. No individual can have an artificial experience, while no company can provide a completely natural one. Resolving this paradox is becoming the key issue for business in the experience economy." 
Sometimes, going above and beyond while providing free experiences or over-servicing undermines the profitability of your entire business. Also, the intangibility of services clubbed with performance ambiguity poses difficulties for consumers in evaluating the service received for which the consumers then subvert towards the quality of provider-consumer relation in terms of feelings and meaningful interactions generated.

When Pine and Gilmore introduced the concept in 1998, it wasn't anticipated that in the coming years, customer experience would mostly steer in the digital direction. While in recent years, most of the emphasis has been laid on big data to figure out that right experience, brands today are discovering that the transactional data from sales and clicks only forms one end of the spectrum. The feedback from the customer is what is crucial. Businesses should understand their customers in terms of their experiences, services but brands also need to view their customers in a holistic manner - their individual nature, their lives, opinions, and values.

\section{Conclusion}

The ever-changing dynamic of client interactions across the assorted touchpoints has created client expertise management even a lot crucial for organizations and might have a big impact on performance. Marketers have begun to depart from the normal relationship management approach. The selling focus has shifted towards the customer-centric approach, analytics has become a vital part of each marketer's arsenal and has offered a lot of nuanced understanding of the activities/processes. The evolution of omnichannel has deeply jolted the standing co and created marketers rethink their ways. selling is moving towards a mix of humanistic styles and virtual reality; it needs an amazing effort on a part of the marketers to evolve with the everchanging dynamics. The shift from moments to complete client journey has been a very important modification for the marketers whereas formulating future ways. The initiative of involving clients in decision-making via insight-communities has additionally enabled marketers to bridge the gap in terms of customer worth. As highlighted earlier, the selling practices have been modified for the great, keeping the client as a concentrate for strategic coming up with and selling strategies; it will reap nice results for the organizations. the utilization of sensible technology (RFID, Kiosks \& IVR), digital platforms, Big Data, AI, and client insights will change organizations to supply a holistic client expertise. Marketers got to unceasingly upgrade their skills for rising challenges and trends within the business world wherever the client is obtaining the due impetus. The role of client expertise management goes to be ever-important within the close to future and sensible businesses can stand out by incorporating it in totality.

\section{Bibliography:}

Addis, M. and Holbrook, M. B. (2001). On the Conceptual Link between Mass Customization and Experiential Consumption: An Explosion of Subjectivity ', Journal of Consumer Behaviour. 
Cognizant 20-20 insights | February 2015, Customer Experience Management: The New Playbook for Indian Manufacturing Organizations

Chauhan Prashant, Dr. Sarabhai Samar, Customer Experience Management: Evolution and the Paradigm Shift in Marketing, Business Perspectives - (ISSN 0972 7612) Volume 17, Number 1

Ittamalla Rajesh, Daruri Venkata Srinivas Kumar Service scopes and Experiential Marketing: A Conceptual Framework and Research Propositions for Memorable Customer Experience, IJETSR www.ijetsr.com ISSN 2394 - 3386 Volume 4, Issue 11, November 2017

Morris B. Holbrook, Elizabeth C. Hirschman. The Experiential Aspects of consumption: Consumer Fantasies, Feelings, and Fun, Journal of Consumer Research, Vol. 9, September 1982

Kotler, P., 2006. Marketing Management, Prentice-Hall of India Private Limited, New Delhi.

Kumar Prarthana, Multisensory Marketing: Creating New Sustainability Perspective in Hospitality Sector, Atna J Tou Stu, 8, 1 (2013), 43-55 ISSN 0975-3281|doi:10.12727/ajts.9.4

Lina Anastassova, Atanas Luizov, Shopping Experience in Retailing: The Case of 2 Food Retailers in Bulgaria, INTERNATIONAL JOURNAL FOR INNOVATIVE RESEARCH IN MULTIDISCIPLINARY FIELD ISSN: 2455-0620 Volume - 4, Issue - 12, Dec - 2018

Maklan, S. and Klaus, Ph. (2011), "Customer Experience: Are We Measuring the Right Things," International Journal of Market Research, Vol. 53, No. 6, pp. 771-92.

Pine, B.J. and Gilmore, J.H. (1999), The Experience Economy, Harvard Business School Press, Boston, MA.

Schmitt.; Bernd H. (2003), Customer Experience Management: A Revolutionary Approach to Connecting with Your Customers,

Shaw, C. \&Ivens, J. 2005. Building Great Customer Experiences: Brand scape.

Srini R. Srinivasan, Rajesh Kumar Srivastava, Creating the futuristic retail experience through experiential marketing: Is it possible? An exploratory study, 2010 Macmillan Publishers Ltd. 1479-1110 Journal of Retail \& Leisure Property Vol. 9, 3, 193-199

http://www.bigbazaar.com/Big Bazaar leverages the power of experiential marketing for the gifting season $10^{\text {th }}$ May 2019

https://study.com/academy/lesson/experiential-marketing-definition-strategies-example.html 
https://www.business-standard.com/article/companies/domestic-apparel-market-to-grow-by-12-on-robustdemand-cmai-118071600951_1.html accessed on 11th June 2019

https://www.globenewswire.com/newsrelease/2018/12/20/1670102/0/en/The-Indian-Textile-and-ApparelMarket-Trends-Share-Size-Growth-Opportunity-and-Forecast-to-2023.html accessed on 11th June 2019 https://www.ibef.org/archives/detail/b3ZlcnZpZXcmMzcxMTAmMTEy accessed on 11th June 2019 